\title{
The Role of Bahrain Kingdom in the Framework of the Cooperation Council for the Arab States of the Gulf (From 2000 to 2006)
}

\author{
Mamoon Ahmed Abo Ra'ad ${ }^{1}$ \\ ${ }^{1}$ Assist.prof. at Bahrain University, Bahrain \\ Correspondence: Mamoon Ahmed Aburaud. E-mail: mamoon.a.aburaud@gmail.com
}

Received: February 4, 2018

Accepted: February 8, $2018 \quad$ Online Published: March 20, 2018

doi:10.5539/ass.v14n4p100

URL: https://doi.org/10.5539/ass.v14n4p100

\begin{abstract}
The current study seeks to identify the role of Bahrain Kingdom in the framework of the Gulf Cooperation Council (GCC) during the period from 2000 to 2006. The importance of the study stems from a set of considerations, the most important of which are: identifying the nature of roles that the member states in a specific regional organization undertake, studying the concept of regionalism and the regional system, and identifying the nature of the role of the member states in the scope of the regional organization in terms of conflict and integration. The problem of the study is that Bahrain is a small state and its resources are limited. It occupies an important strategic location in a very significant strategic region in the context of the international interactions. Its direct geographical neighbor is characterized by great resources. In addition, its surrounded regional environment is characterized by tension and instability. Thus, the question in such circumstances is: how Bahrain Kingdom can create and practice its role in the framework the GCC, which is the regional organization activated by interactions between geographically reproached member states? To achieve the required results, the study adopted the international system approach and the historical approach. The study has concluded a set of findings. The most significant findings are: 1- the GCC came as a result of a set of internal, regional and international factors, and not one factor. 2- The GCC has been able to achieve the internal and external cooperation between its member states. 3- The regional and international developments have a tangible effect on Bahrain and its relation with the GCC. 4- Bahrain plays a prominent role in activating the march of cooperation and integration between the members of the Council in various economic, political, social, cultural and media fields.
\end{abstract}

Keywords: Bahrain, Gulf Cooperation Council, regional system, integration

\section{Introduction}

Bahrain Kingdom has adopted a clear policy since its independence in 1971. This policy is committed to the Arab and Islamic constants. This policy believes the necessity of dialogue and the consolidation of cooperation between states and peoples. In addition, it refuses intervention in the internal affairs of the other countries and acknowledges the international legitimacy as the real way to achieve international security and peace. These principles are committed to Bahrain in its different circles, especially the Gulf circle, which occupies a pivotal importance for it. The Arab Gulf region represents the natural extension and the strategic depth for Bahrain. Therefore, Bahrain has put the Gulf region on the top of its priority and it was the first country welcomed to the establishment of the GCC. It has provided all types of consolidation and support in order to develop and activate the GCC. Furthermore, it has sought to establish and consolidate its relations with the rest of the countries of cooperation council. Bahrain has adopted the policy of integration, cooperation and understanding between the region's countries on the basis of the mutual respect, keeping the common interests, non- intervention in the countries' internal affairs, seeking to achieve peace and stability in the Gulf region. Additionally, Bahrain has adopted the principle that the security of the Gulf region is a personal responsibility of its countries and political entities in the first place and the settlement of disputes peacefully.

The Bahraini National Charter, which has been developed by the majesty of the King and has been accepted by the Bahraini people, has included a set of principles. The most important of them are: 1- The government and people of Bahrain firmly believe that the peoples of GCC countries share the same blood relationships that are further galvanized by common history, culture and custom. These have been sufficient grounds for Bahrain to be a founding member of GCC along with other sisterly Gulf Arab Countries. 2- A serious cooperation among GCC 
countries is of utmost importance to the highest interests of all sisterly member - states, including maximum development for the countries and peoples of GCC. 3- The state of Bahrain shall always work, with all its force, to strengthen GCC and to support the just causes of its sisterly member - states. The state of Bahrain considers this as one of its core political constants that are organically related to Bahrain belief that its security and prosperity are part and parcel of those of other sisterly GCC member - states. 4- The state of Bahrain shall work closely with its sisterly GCC member - states for greater coordination, rapprochement and integration within GCC, particularly in those areas that still require a more effective coordination such as economic integration, defensive cooperation, information coordination, as well as people's participation in GCC organization.

Accordingly, the study seeks to identify the role of Bahrain in the GCC during the period from 2000 to 2006. The study focuses on four parts. The first part defines the regional system. The second deals with the establishment of the GCC. The third examines the objectives of the GCC. The fourth deals with the role of Bahrain in the framework of the GCC. This part includes: the economic areas, the political issues such as the Iranian - Iraqi war, consolidating the unity and stability of Iraq, the Iraqi invasion of Kuwait, the crisis of the Iranian nuclear file, and supporting Union Arab Emirates in the issue of the islands occupied by Iran. It, also, includes the security issues.

\section{The Concept of the Regional System}

Definitions developed by scientists and researchers about the regional system were many. The study will explores in the following part these definitions. Also, it analyzes and determines the aspects that researchers agree and disagree in order to determine the study's vision about this concept.

The roots of this concept in the political thought concerning the international affairs can be attributed to a long period of time where the concept of regionalism was one of the main topics in the field of the international organization. There was argument about universalism versus regionalism. Which approach will we adopt to organize the international society and to keep peace among countries. The supporters of universalism suggest that universal organization including all countries must be adopted. However, the supporters of regionalism see that the establishment of regional organizations is the best way to achieve the international peace and security. The second root of regional system concept is the study of integration between states where the regional integration is one of the main issues for integration. Two main trends in the definition of integration can be distinguished. The first trend is a general trend which defines integration as one of the forms of cooperation or coordination between different countries without prejudice to the sovereignty of each country. This definition has been criticized due to the fact that it is comprehensive and wide, which all cooperative relations work as integrated relations. This leads to a meaningless integration concept. Also, this trend prefers distinguishing between integration on the one hand and cooperation and coordination on the other. The second trend is more specific. It considers integration as a process through which relations between countries can be developed. The supporters of this trend indicate new common forms between institutions and interactions that affect the policy of countries. Thus, integration process transfers authorities and competences from countries to regional institutions and bodies (Mater \& Helal, 1973).

According to Mohamed El- Sayed Saed, the regional system is an interactive framework between some countries. It is characterized by regular and concrete interactions. Therefore, change in a part of it affects the rest of parts and leads to an internal and external acknowledgement the regional system as distinguished system. This was due to consensus between the regional system and international one. Concurrently, there is a clear deal of interruption between them. The concept of interaction between the concerned countries is distinctive, which puts total interrelated limits between the concerned countries and the other regional systems in particular, and the international system in general (Saed, 1992).

The regional system constitutes a subordinate system within the framework of external environment from which the international system forms. It is a set of countries which belongs to one territory. There are common interests linking these countries each other where they depend, in their international interactions, on cooperation and distinction, and perhaps on the regional integration later in the areas of security, economy and all other areas. Therefore, the regional system is only a way of practice in dealing between the different countries, which belong to one territory (Al-Hadithy, 1998).

The regional system is based on main criteria in determining its existence. The most important criteria are:

- Specific geographical territory on which the relations of the geographical neighborhood is based. These relations form the basis of distinction between the regional systems.

- The world acknowledges that the territory constitutes a distinctive case for the world order. 
- The existence of common cultural, social and economic elements which determine the felling of regional affiliation identity.

- The existence political, economic, cultural and social interactions between the countries of the territory. These interactions determine the common regional interests and their orientations.

However, "Nye" indicates that the concept of regionalism does not depend only on the geographical rapprochement and increased economic linkages, but also it depends on a set of historical experiments, the distribution of power and wealth inside and outside society, cultural and social customs, ethnicity, and ideological or political preferences (Nye, 1968).

According to Boutros Boutros Ghali, regionalism is a political system between many countries, which locate in the same territory. The geographical neighborhood sometimes is a main matter for it, and sometimes is a secondary matter. In other words, regionalism is one of the political and social solidarity forms. It is based on social, humanitarian, historical or economic factors. These factors form common consciousness and closed solidarity between these countries (Ghali, 1952).

\section{Establishing GCC}

Bahrain, Kuwait, Oman, Qatar, Saudi Arabia and the United Emirates established the Cooperation Council for the Arab States of the Gulf, more commonly referred to as the GCC, on May 25, 1981. The founding charter focused on economics, education, and culture, with the aim of achieving coordination, integration, and interconnection to achieve unity between them. Political and security issues were not expressly mentioned in the charter, although subsequent meetings and communiqués reaffirmed these areas of cooperation within the body. The GCC consists of a Supreme Council, Ministerial Council, and General Secretariat. The Supreme Council is composed of the rulers of member states and serves as the highest decision making authority within the GCC. The GCC Ministerial Council, consisting of the member states' foreign ministers, meets quarterly. Each member also has the option to call an extraordinary session of either council, so long as another GCC member supports the call. Within these meetings, each member state holds a single vote. There is a strong preference for consensus, but decisions are taken by majority rule when necessary. A secretary- general chairs the GCC, and the chairmanship rotates among the six states. The GCC Secretariat and general headquarters are based in Riyadh, Saudi Arabia (Martini, 2016).

\section{The Objectives of the GCC}

The main objectives of the GCC (Al- Sherida, 1995), according to the fourth article from the main system of the GCC, are the following:

A. Achieving coordination, integration and interconnection between member states in all areas.

B. Deeping and documenting interconnection, linkages and cooperation between its peoples in all areas.

C. Developing Similar systems in different areas, including:

- The Financial and economic affairs.

- The commercial affairs, customs and means of transportation.

- Educational and cultural affairs.

- Social and medical affairs.

- Touristic and information affairs.

- Legislative and administrative affairs.

D. Supporting the scientific and technical progress in the areas of industry, mining, agriculture and water and animal resources. Also, establishing scientific researches centers and common projects, as well as encouraging the cooperation with of the private sector.

It is noticeable that these objectives are general, and not specific. They aim to establish a cooperative entity between the six Gulf countries in all areas. Furthermore, the council's basic system does not include the political, security and defensive affairs as a main objective. This is due to the fact that the non- thorny issues increase the opportunities of achieving the objectives of the council. In addition, the council has been created as a result of unstable, regional and international conditions. The foreign countries are waiting opportunities to establish military bases in the region. The Iranian- Iraqi War has erupted. Also, the GCC countries are feared of the Iranian expansion in the region. Therefore, the GCC countries did not explicitly declare the enhancement of the political and security aspects between them. According to the first paragraph of the fourth article of the council's main 
system, it affirmed that one of objectives of the council is the achievement of coordination and integration between the member states in all areas. All areas imply all cooperation aspects, including the political, security and defensive aspects.

\section{The Role of Bahrain in the Framework of the GCC}

Issues related to this role are various where there are economic, political and security issues. The study will explore in details these issues as follows:

\subsection{Economic Areas}

The economic file occupies a prominent status in the agenda of the GCC since its establishment because this file includes one of the most important strategic problems from which the member states suffer. This problem is the limited market because the number of population is few. Therefore, the GCC has sought, since its establishment, to overcome this problem by transforming the divided market. This led to expanding the scope of the market before the national projects by the removal of tariff barriers among GCC countries' markets.

The GCC has sought, since its first beginning, to achieve coordination and integration between its member states. It has provided similar systems and coordinated legislative base for economic, financial, commercial and customs activities. For example, the economic agreement of the GCC countries has been signed on November, 1981 after six months from its establishment. This agreement has established the bases of the economic relations between the member states and under which free trade zone has been established on March, 1983. In General, the economic cooperation between countries tends to adopt one of two approaches. First, the commercial approach which depends on trade liberation. Second, approach which tends to liberate transformation of production factors by giving a priority to create various productive base. The GCC countries has adopted the commercial approach in the beginning by establishing Gulf Free Trade Zone in 1983, which transformed to the customs union in 2003 (Al-Ras, 2005).

\subsection{Political Issues}

Bahrain with the rest of the GCC countries have sought to formulate common unified positions towards the political issues that represent importance for the GCC countries in the regional, Arab and international frameworks. The study will deal with the political issues concerning the regional affairs. These issues are as follows:

\subsubsection{Iraq- Iran War}

At the first year of the establishment of the GCC, the Iraqi- Iranian War has received attention the sessions of its superset council since first Abu Dhabi summit. The countries of the council have used its political and morale capabilities in order to find a solution for that bloody war which resulted in humanitarian and financial losses for the two parties and destabilized the regional security. The GCC countries have moved through committee of seven, which has been formed with aim of cease- fire. In addition, the political efforts of the GCC countries helped to shed the light on war. These efforts resulted in the Security Council's resolution 540 in October 1983. This resolution called cessation the military operations in the Gulf and non objection vessels, economic facilities and ports. The Security Council issued, also, the resolution of 552 in June 1984 as a result of a complaint introduced by the GCC countries. This complaint was due to attacks on the trading vessels from and to the ports of Saudi Arabia and Kuwait. Furthermore, the GCC has played a key role in issuing the resolution 598 in June 1981 by Security Council. This historical resolution has been accepted by the two sides, resulting in ceasing that destructive war.

\subsubsection{The Iraqi Invasion of Kuwait}

When the previous regime in Baghdad invaded and occupied Kuwait, the GCC countries has a rapid response. This movement stems from the argument that any attack on a member state is an attack on all the GCC countries. The GCC countries were nucleus of the political diplomatic movement that refuses invasion and demand withdrawal without condition or restriction. Foreign ministers of the GCC held an emergency meeting in Cairo (3 August, 1990) on the margin of the meetings of the Arab League Council. The efforts of the GCC countries succeeded in holding the emergency Arab Summit in Cairo (10 August, 1990). Furthermore, the GCC countries have played a key role in urging the Security Council to issue a series of resolutions for the security of the withdrawal of the Iraqi regime's forces and the return of legitimacy without condition or restriction. One of these resolutions is resolution 660 issued 3 August, 1990, which condemned invasion and demanded immediate and unconditional withdrawal. The Gulf efforts and positions have been crystalized in the resolutions of the eleven summit of the GCC held in Doha in December 1990. This summit affirmed that the GCC fight against invasion and is determined to resist it and demolish its repercussions and effects. The GCC countries stress that any attack 
on a member state as attack on all member states and that the security of the council's countries is indivisible (Note 1).

The GCC Council has played a prominent role in the process of Kuwait liberation by using its political and diplomatic weight and exploitation the military and financial capabilities for liberation that achieved in February, 1991. Also, the council has been demanding the implementation of the Security Council's concerned resolutions and demolishing the consequences of invasion and occupation.

\subsubsection{Consolidating Unity, Sovereignty and Stability of Iraq}

After the departure of the ex- regime in Baghdad, the GCC countries were keen, in more than occasion, to help the sisterly Iraqi people in its political disaster. This has been done by supporting the central role of the United Nations in the political process in Iraq, as shown in the resolution of the Security Council 1546 issued in on 8 June, 2004. The GCC, also, supported the legislative elections in order to accomplish the political constitution. In addition, the GCC has sought, by participation in conferences of donor countries, meetings with neighborhood countries and the bilateral connections, to accelerate the process of economic reconstruction in Iraq. The GCC supported International Covenant Document with Iraq that issued in conference held in Sharm Al- Sheikh on 4-5 May, 2007. This document included a five- year plan providing financial, political and technical support for Iraq. In return, the Iraqi government undertakes political, economic and security reforms (Al- Hemdani, 2008).

The GCC expressed its extreme concern about violence and terrorist crimes, including attack on holy places and houses of worship. Also, council stressed the respect for the unity, sovereignty and independence of Iraq, the refusal of retail and division, non- interference in the international affairs, and considering national consensus as key for solution in Iraq.

\subsubsection{The Crisis of Iranian nuclear File}

The GCC has fixed principles such as the respect for the international legitimacy and solving disputes peacefully. Therefore, the GCC stressed that the peaceful solution for this crisis must be reached. It, also, urged upon Iran the importance of the international dialogue, full cooperation with International Atomic Energy Agency and the commitment to the international criteria for atomic energy. The GCC called upon Israel to join Treaty on the Non- Proliferation of Nuclear Weapons and to subject all its nuclear facilities to inspection system by International Atomic Energy Agency.

There is no doubt that the GCC countries are part and parcel of the security of the Middle East region. If the issue of Israeli nuclear capabilities represents a source of threat to all countries of region, including Gulf States, the Iranian nuclear program will represent a threat to Gulf States. Thus, if Iran managed to possess nuclear weapons, this matter would have negative repercussion on the security and stability of the Gulf region. In particular, some American and international estimations indicated that Iran can succeed in producing nuclear weapon through five years. The Iranian nuclear program became an Iranian national project that has been supported by all religious and political forces in Iran. Therefore, this program must be stopped. Additionally, the United States and Israel might direct a preemptive military strick against the Iranian nuclear facilities, resulting in destructive repercussions on the Gulf area.

Accordingly, The GCC countries see that the development of the Iranian nuclear capabilities will affect negatively on the regional security and stability. The GCC interests in its security in particular and the security of the region in general. Therefore, it refuses the escalation of Iranian nuclear file crisis to reach the phase of direct confrontation between Iran and forces opposing its program because they realize that this confrontation will make the region vulnerable to mass destruction. Also, it refuses the Iranian possession of the nuclear weapon because this possession may give Iran comprehensive regional hegemony.

Final statement of Abu Dhabi's summit reflected the rationality of the GCC countries. The GCC took into consideration the reality of the region's Geopolitics. In particular, Iran- Gulf relations are not limited to the nuclear file in spite of its importance. It called upon Israel to join the system of nuclear non- proliferation. Thus, it sends a message to the international forces that the nuclear danger will not come from Iran only, but come from Israel also. Israel is the only illegal nuclear force in the region. Israel possesses the nuclear weapon under the auspices of the United States, which continued to follow double standards policy in handling the issues of region.

\subsubsection{Supporting the United Arab Emirates in the Issue of occupied Islands by Iran}

The three Islands of Greater Tunb, Lesser Tunb and Abu Musa of the United Arab Emirates have become an essential issue on the agenda of the Ministerial Council and the Supreme Council. The GCC countries have supported the UAE's position on the Islands issue, and called upon Iran to end its occupation of these Islands and 
engage in direct negotiations with the UAE on the issue of the occupied Islands or the referral of the case to the International Court of Justice. An important step in this context is the decision of the Ministerial Council at its seventy- first session, held in Jeddah on 3 July 1999, to establish ministerial committee from Saudi Arabia, Oman, Qatar and the Secretary- General of the Council with aim of developing a mechanism to begin direct negotiations to resolve this issue. However, Iran refused to receive the committee. In an expanded international action, the GCC countries appealed to countries and regional and international groups to persuade Iran to accept the peaceful efforts of the United Arab Emirates to resolve the issue of the three Islands (Note 2).

\subsection{Security Issues}

There are a number of security issues that require cooperation between the GCC countries to confront the security threats, such as the drug trade, money laundering and counterterrorism. On these three issues, the Kingdom of Bahrain has sought to enhance cooperation within the Council to face the security threats resulting from them. This cooperation has included confronting these threats at the internal, GCC countries, regional and international levels. In this regard, the study presents the issue of anti- terrorism as a model.

\subsubsection{Cooperation in Combating Terrorism}

The phenomenon of extremism and terrorism has received considerable attention from the Gulf States during the last two decades. It also had negative, political, economic, social and humanitarian consequences and repercussions. The first reference of this phenomenon explicitly and directly was at the Muscat summit in 1985, which condemned all acts of terrorism in the region. The Council pledged to strengthen its relations with any member state that is to be exposed to such acts, and considered this phenomenon as a threat to all GCC countries. The GCC suggests that the security of the GCC countries is indivisible. It deals with the phenomenon of terrorism as an internal or regional matter at best. According to the GCC countries, terrorism is one of the security challenges which fall within the areas of security cooperation among the countries of the region such as cooperation in combating the organized crime, drugs and money laundering.

The two Summit of Manama was held in 1994 to confirm the Council's awareness of the seriousness of this phenomenon and its complexity and dimensions. This summit included a separate item that comprised the special decisions taken by the Gulf leaders to confront this phenomenon which started to take cultural and social dimensions that require regional cooperation in various fields. The final statements of the GCC countries confirmed several principles that formed a common Gulf approach to how to deal with this phenomenon. These principles are:

- Condemnation of terrorism of all its kinds and forms aimed at spreading chaos, fear and the loss of innocent lives.

- The solidarity of the GCC countries with each other towards this phenomenon based on the principle of the common destiny of the GCC countries. In 2001, the Muscat Summit adopted the security strategy to combat extremism accompanied by terrorism and money laundering, while the Supreme Council at its $24^{\text {th }}$ session in 2003 accepted the agreement of the GCC on fighting against terrorism that signed by the Minister of Interior in their fifth consultative meeting in Kuwait.

- Supporting every regional and international effort to combat terrorism by crystalizing and coordinating positions on the definition and determination of terrorism. In this context, the two countries of Kuwait in 1997 and Abu Dhabi in 1998 called for the conclusion of international convention to combat terrorism (Saber, 2004). The Muscat Summit in 2001 also supported the International Alliance for the Eradication of Terrorism and the Abu Dhabi Summit in 2005 welcomed the results of International Conference on Combating Terrorism hosted by Riyadh in February 2005.

- Enhancing cooperation and coordination between the various security, information and educational agencies in the GCC countries in order to confront terrorist organizations and operations.

- Dealing with this phenomenon through strategies based on a holistic and inclusive vision in which all members of society, especially opinion leaders, thinkers and scientists in the Islamic World, participate.

\section{Future Scenarios}

In this context, the researcher can refer to three basic scenarios, which are:

\subsection{The Continuation of the Status Quo Scenario}

This means the continued role of the Kingdom of Bahrain in maintaining the continuity of the GCC and increasing its effectiveness, and thus continuing to follow and adopt the policy of support for the GCC at all levels, political, social, economic, security, cultural and media, and all that would preserve the existence of the 
Gulf region. The issue of Gulf stability is one of its top priorities on the political agenda. Bahrain adopts a moderate and wise approach that would remove any tensions or obstacles to the continuation of the GCC.

\subsection{Development Scenario}

This Scenario is based on putting a vision to develop the GCC where it became an integrated system in various areas among its members. It requires determination of perceptions of what should be the Council during the next phase and the requirements to achieve that matter.

\subsection{Scenario of Retreat of Bahraini Role}

This scenario assumes that there is a turbulent environment of an internal conflict nature and that such tensions and conflicts are intensifying within the constituent units of the regional environment. This scenario is based on a number of indicators, which are: the growing dispute between the opposing forces and ruling regimes within several regional environment states, the increasing intensity of local, regional and international conflicts, as well as the continued decline of the security file in Iraq. This turbulent environment may lead to the rise of opposing currents and forces to power. Thus, many ruling systems in the countries of the region will be changed. Any changes, which may take place under a state of chaotic feature of a political environment will lead to the continuation of the state of political polarization, especially at the external level. These changes may reach to the armed violence between the opposing currents.

The GCC countries are not isolated and will be affected by these tensions. This situation can be transmitted to them for several reasons. The most important reasons are: the link between the GCC countries the countries of conflict, especially Arab countries, in addition to that one of candidates for such changes is Iran. It has relations and influence which may lead to the export of such tensions in light of the sectarian link between the Shiites Iran and the Gulf. This will lead to the creation of a turbulent environment, as mentioned earlier, which leads to the decline of the role of Bahrain or any other Gulf state in the process of activating and developing the Council, and the focuses on the security concern. One of the objectives for which the GCC was established is the security concern (Abo Amoud, 2004).

The study suggests that the scenario of the continuation of the status quo is the closet scenario. Thus, Bahrain can play a key role in activating the GCC and preserving its identity as a Gulf regional organization, as the Gulf region is witnessing many security, political, economic and social changes. The most important of these challenges are: the foreign military presence in the Gulf region, the Iranian nuclear crisis, the repercussions of the Iraqi file, energy security and oil prices file, the danger of terrorist organizations, and the dilemma of seeking a stable formula for relations between the GCC countries and Iran. All these challenges make the future of the Bahraini role open to all possibilities.

However, by the data and indicators in our hands, we can say that the scenario of the continuation of the status quo is most likely due to the following factors (Abo Amoud, 2008):

- The balance of power in the region, whether at the military, demographic, economic or scientific level.

- The nature and limits of cooperation and coordination between the GCC countries.

- The future of global demand of the Gulf's oil and energy security dilemma. This factor will draw the limits of global concern for the issue of security in the Gulf.

- Internal developments in the Iranian arena and their impact on the future of the security situation in the Gulf and Iran's relations with the GCC countries.

- The future of the Iraqi crisis. The shape of this crisis will have a great impact on the future of the entire region. A stable and unified Iraq, which is moving effectively on the path of development, is better than a disintegrated Iraq that is a hotbed of extremism and terrorism.

- $\quad$ US military presence in the Gulf.

- The future of the reform process in the GCC countries.

\section{Conclusions}

The study has reached many conclusions, the most important of which are:

- The establishment of the GCC was a product of a combination of local, regional and international factors. Almost all studies concluded that security reasons were among the main factors behind the establishment of the GCC. However, the constitutive document of the Council affirmed in its preamble that the security cooperation will only be achieved through cooperation in the political, economic, social and military fields. We can say that the composition of the Council was a product of the critical local, regional and 
international conditions in order to face the greed of the major powers and the neighboring regional states. In addition, the importance of geographical convergence, the similarity of regimes and the demographic, economic and social similarities had strategic advantages of the GCC countries in political and economic integration.

- Regional and international developments and changes have a significant impact on Bahrain and its relations with the GCC. The regional threats surrounding the GCC countries, including Bahrain, have been aggravated due to the deterioration of the security and political situation in Iraq, the new ideas of the regional security system after the US occupation of Iraq and the threats of the Iranian nuclear file. Therefore, Bahrain, as one of the countries of the region, is directly affected by the political and strategic interactions taking place in its foreign environment. In addition, there are important influences emanating from the international framework that can affect the future of the Bahrain role with the GCC

- $\quad$ There is a pivotal role for the Bahraini political leadership and institutions in pushing forward the process of joint GCC action in order to achieve integration and growth in all fields

- $\quad$ There are a number of challenges and that could impede Bahrain in bringing about the integration process. There are the challenges of internal environment, namely the small size of Bahrain, the lack of natural resources and weak economic and military capabilities. Furthermore, there are regional challenges, the most important of which are: the Islamic Revolution in Iran, the outbreak the Iran- Iraq war, the Iraqi invasion of Kuwait, the American invasion of Iraq and the Iranian nuclear file

- The necessity of modernizing and restructuring the Council in light of the economic, political, security, local, regional and international conditions. Many studies call for updating the Council's functions such as the establishment of constitutional court, parliament, a satellite channel and supreme executive agency.

- The study has reached a number of scenarios regarding the role of Bahrain with the GCC countries. According to the researcher, the most likely scenario is the continuation of the status quo scenario, with the need to develop the mechanisms of the Council that leads to the increase of the Council's ability to continue and adopt with internal, regional and international variables during the next phase.

\section{References}

Abo Amoud, M. S. (2004). Iraq after the American Occupation. In: A Group of Researchers, the Iraqi Crisis after the American Occupation. Cairo: Gulf Center for Strategic studies.

Abo Amoud, M. S. (2008). Building Scenarios in Political Analysis: A Comparative Analytical Study. Alexandria: Al- Shanhaby Library.

Al- Ras, A. (2005). The Experience of Economic Integration of Cooperation Council for the Arab States of the Gulf: Selected researches from of Economic Integration of the GCC. Kuwait: The Arab Institution for Planning.

Al-Hemdany, H. (2008). The Third Gulf War: Series 141 Resolution of Security Council. No. 1546 to form an Iraqi Government and Ending Occupation. Retrieved from http: www. Nirgalgate.com.

Al-Sherida, A. (1995). The Cooperation for the Arab States of the Gulf: its Mechanisms, Declared Objectives and Relations with the Regional and International Organizations. Cairo: Madbouli Library.

Ghali, B. B. (1952). The Definition of the Regional agreements. The Egyptian Journal for the International Law, 8, 280-286.

Martini, J. et al. (2016). The Prospects of the Cooperation of the Arab Gulf. Retrieved from Rand Institution.

Mater, G., \& Helal, A. (1973). The Arab Regional System: A Study in the Arab Political Relations. Al-Mostaqbal Al- Araby Journal, 18-19.

Nye, J. (1968). International Regionalism: Readings. Boston: Lih Brown.

Saber, M. (2004). The Gulf Security Agreement: Does it eliminate the Danger of Extremism and Terrorism? Gulf Affairs Journal, 38, 109-110.

Saeed, A. (1987). The Countries of the geographical Neighborhood. Beirut: Center of Arab Union Studies.

Saeed, M. E. (1992). After the Gulf Crisis. Kuwait: National Council for Culture, Arts. 


\section{Notes}

Note 1. See Doha declaration issued by the eleven session of the Supreme Council, Qatar, 22-25 December, 1990 .

Note 2. See the final statement of twenty- one session of the Supreme Council of the GCC, Bahrain, Almama on 30-31 December, 2000.

\section{Copyrights}

Copyright for this article is retained by the author(s), with first publication rights granted to the journal.

This is an open-access article distributed under the terms and conditions of the Creative Commons Attribution license (http://creativecommons.org/licenses/by/4.0/). 